\title{
STUDENT CORNER
}

\section{Prevalence and Predictors of Willingness and Attitudes towards Organ Donation among Medical and Non-Medical University Students in Karachi}

\author{
Rida Fatima Syed', Rabbia Siddiqi², Zohaib Jawed Abubaker', Hamza Shabbir', Faryal Zafar', Nisa Fatima \\ Sunderjee', Muhammad Fazal Hussain Qureshi', Muzna Shah', Rida Tafveez', Zain Jawed Abubaker', \\ Muhammad Zubair Shaikh' \\ 'Student, Ziauddin University, '2Dow Medical College, Dow University of Health Sciences, Karachi, Pakistan.
}

\begin{abstract}
Background: Even though organ transplants save thousands of lives globally, there exists a wide mismatch between an increasing demand for organ transplants and limited number of organ donors. The aim of the study was to assess the reasons and inspect differences between donors and non-donors in both students of medical and non-medical universities.
\end{abstract}

Methods: A cross-sectional study was conducted over a period of 6 months (May 2018-March 2021). Sample of 400 participants enrolled from three medical colleges, two business/social sciences institutions and one engineering university of Karachi. Categorical variables were compared using the Chi-squared test. Continuous variables were compared using a student t-test. Variables with a univariate $p$-value $\leq 0.10$ were included in multiple logistic regression models. Adjusted odds ratio (OR) with $95 \%$ confidence interval were reported.

Results: With a very high response rate $383(96 \%)$ for knowledge about organ donation, a subdued response 201 (52.3\%) for willingness to donate. Most common source of knowledge regarding organ donation was social media 249(65\%), followed by university $207(54 \%)$, family/friends $184(48 \%)$ and television $172(45 \%)$. Multiple logistic regression model identified being comfortable discussing organ donation as a positive predictor of willingness to donate (OR: 2.71, $p=0.005$ ), and the belief that organ donation disfigures the body as a negative predictor (OR: 0.40, $p<0.001$ ).

Conclusion: Attitude towards organ donation was not up to the mark among the participants $(201 / 383=52.3 \%)$. Better knowledge may ultimately yield into the act of donation. Valuable measures should be taken to teach young people with significant information with the contribution of social media, institutions and families.

Keywords: Organ Donation; Donor Card; Organ Transplants; Ethics.

Corresponding Author:

Rida Fatima Syed

Ziauddin University,

Karachi, Pakistan.

Email: rsyed.97@gmail.com

https://doi.org/10.36283/PJMD10-3/018

\section{INTRODUCTION}

Although organ transplants save thousands of lives globally, there exists a wide mismatch between an increasing demand for organ transplants and limited number of organ donors. The Global Obser- vatory on Donation and Transplant states that in 2017 Pakistan carried out only 1284 organ transplants - a per million population rates of 6.52 , compared with global rate 25.06 for the same year ${ }^{1}$. In Pakistan, most harvested organs come from living donors, due to the low deceased donation rate ${ }^{2}$. 
Countering the constant shortage of donor organs by increasing willingness to donate among the general population is likely to reduce the high mortality from organ failure and curb illegal organ trafficking.

A previous survey of the general adult population of Karachi, Pakistan revealed a willingness to donate one's organs after death ${ }^{3}$. Worldwide, willingness to donate has variously been associated with gender, ethnicity ${ }^{4}$ socioeconomic status ${ }^{3}$ religious/cultural beliefs ${ }^{5}$, being a medical student ${ }^{4}$, confidence in brain death diagnosis ${ }^{6}$, prior discussion regarding organ donation, fear of donors getting inadequate care $^{7}$, and knowledge of organ donation ${ }^{8}$ across different strata of society. The lack of recent literature investigating predictors of willingness to donate among the Pakistani population was alarming hence; we conducted this study to investigate root causes. Our target population was university students as these young adults represent the upcoming generation of organ donors, and they are often the first group to be targeted by public awareness campaigns.

The primary objective of this study was to determine the prevalence and predictors of willingness to become an organ donor amongst university students in Karachi. The secondary objective was to compare attitudes towards organ donation between medical and non-medical students. Identifying potential perceived barriers to organ donation and sources of knowledge on this topic for students were additional objectives.

\section{METHODS}

A cross-sectional study was conducted to assess willingness and attitudes towards organ donation amongst university students in Karachi, Pakistan. The study period was May 2018-October 2018. The study was a student-based research and the Ethical Board of the Research Council of Pakistan granted ethics approval.

A target sample size of $n=400$ was calculated with $95 \%$ confidence interval $(\mathrm{Cl})$ and sample error of $5 \%$, assuming a prevalence of $62.3 \%$ for willingness to be an organ donor, based on previous research ${ }^{3}$. Non-probability convenience sampling was used a paper-based questionnaire was disseminated amongst the sample population; in addition, online Google forms were also used to collect data. Students enrolled in any of 3 medical, 2 business/social science and 1 engineering universities of Karachi were inducted, with their informed consent, into our study. Students of either gender and all years of study were included. Confidentiality and anonymity of participants was ensured.
The questionnaire form was designed based on previous literature ${ }^{3.5}$ as well as the authors' knowledge of the local cultural context. The first part of the form recorded demographic details and field of study (medical vs. non-medical). The next part assessed awareness of organ donation and organ donation cards, willingness to become a donor, and prior acquaintance with a donor or recipient. Further questions dealt with knowledge regarding donor age limits, live and deceased donor eligibility criteria, donor/recipient risks, recipient priority criteria and blood group compatibility in the context of organ donation. The final part of the questionnaire consisted of statements expressing various attitudes towards organ donation, and the respondents were expected to either agree or disagree. The questionnaire also listed potential barriers to organ donation and potential sources of information; for each item on the list, the respondents could select either 'yes' or 'no'.

Categorical variables were compared using Chi-squared test. Continuous variables were compared using a two-tailed student t-test. Variables with a univariate $p$-value $\leq 0.10$ were included in multiple logistic regression model to identify independent predictors of willingness to becoming an organ donor. Adjusted odds ratio (OR) with $95 \%$ confidence interval were reported. $p<0.05$ was considered statistically significant. Data analysis was performed using Statistical Package for Social Sciences 19 (SPSS Inc, Chicago, IL).

\section{RESULTS}

The questionnaires were distributed to a total of 400 students, of whom 383 completed and returned the forms, giving $96 \%$ response rate. $n=262(68 \%)$ of the sample population consisted of females while $32 \%$ $(n=121)$ were male. Mean age of the participants was 21 years with Standard deviation of 4.0. Among the study population, $50 \%(n=191)$ belonged to Medical field while other $50 \%(n=192)$ belonged to Non-Medical field of studies. $n=153$ (43\%) were Urdu speaking followed by Punjabi $28 \%$ ( $n=91)$, Sindhi $16 \%$ $(n=62)$, Pathan $6 \%(n=24)$, Memon $3 \%(n=11)$ and $8 \%$ $(n=32)$ belonged to other ethnicities. Majority of participants were Muslims $92 \%$ ( $n=354$ ) followed by Hinduism $5 \%(n=19)$, Christianity $2 \%(n=6)$ and $1 \%$ $(n=4)$ were atheist. While $82 \%$ of the participants belonged to Middle socioeconomic status while $18 \%(n=67)$ belonged to upper socioeconomic status and $<1 \%(n=2)$ belonged to low socioeconomic class. Among the study population, $97 \%$ $(n=370)$ respondents reported being aware of what organ donation was.

Overall, 201 (52.3\%) participants stated a willingness to become an organ donor. However only 126 (33\%) participants knew what an organ donor card 
was, and only $7.0(2 \%)$ reported having an organ donor card. On bivariate analysis, the following factors were significantly associated with willingness to donate: gender; being acquainted with an organ donor or recipient; belief that organ donation disfigures the body; feeling comfortable in discussing organ donation with friends or family: and knowledge about minimum age for donation, donor-recipient blood group compatibility and potential recipient priority criteria $(p<0.1)$. Factors not significantly associated with willingness to donate included age, ethnicity, and religion, field of study (medical vs. non-medical), self-reported socioeconomic status, knowledge of donor eligibility criteria and knowledge of risks of organ donation.

Adjustment for significant respondent characteristics in a multiple logistic regression model (Table 1) identified being comfortable discussing organ donation as a positive predictor of willingness to donate (OR: 2.71, $p=0.005$ ), and the belief that organ donation disfigures the body as a negative predictor (OR: $0.40, p<0.001$ ). The $p=0.782$ indicates that our model fits the data well.

Table 1: Multivariate logistic regression analysis of factors associated with willingness to become an organ donor.

\begin{tabular}{|l|l|l|}
\hline Variable & \multicolumn{1}{|c|}{ Odds ratio (95\% Cl) } & p-Value \\
\hline Gender & 1.00 & 0.22 \\
\hline Female & $0.75(0.48-1.19)$ & \\
\hline Male & 1.00 & 0.08 \\
\hline Prior acquaintance with an organ donor or recipient \\
\hline Absent & $1.57(0.95-2.58)$ & \\
\hline Present & 1.00 & 0.005 \\
\hline Being comfortable discussing organ donation with friends and family \\
\hline Uncomfortable & $2.71(1.35-5.43)$ \\
\hline Comfortable & 1.00 & $<0.001$ \\
\hline Belief that organ donation disfigures the body \\
\hline Present & $0.40(0.24-0.67)$ \\
\hline Absent & 1.00 & 0.15 \\
\hline Correct identification of recipient priority list criteria \\
\hline Absent & $1.46(0.87-2.47)$ \\
\hline Present & 1.00 & 0.10 \\
\hline Correct identification of minimum donor age \\
\hline Absent & $1.46(0.93-2.28)$ \\
\hline Present & 1.00 \\
\hline Knowledge of blood group compatibility between donor and recipient \\
\hline Absent & $0.63(0.31-1.28)$ \\
\hline Present
\end{tabular}

Cl: Confidence Interval

Attitudes of medical and non-medical students towards organ donation are summarized in Table 2. Medical students were significantly more likely than non-medical students to report being comfortable in discussing organ donation with friends and family $(p<0.001)$, and also significantly more likely to regard payment in exchange for organs as unethical $(p<0.001)$. Both medical and non-medical students were equally likely to be aware of current Pakistani laws concerning organ donation, and equally likely to support promotion of organ donation. 
Table 2: Attitudes of medical and non-medical students towards organ donation.

\begin{tabular}{|c|c|c|c|c|c|}
\hline \multirow[t]{2}{*}{ Variables } & \multicolumn{2}{|c|}{$\begin{array}{l}\text { Medical students } \\
(n=193)\end{array}$} & \multicolumn{2}{|c|}{$\begin{array}{l}\text { Non-medical students } \\
(n=190)\end{array}$} & \multirow[t]{2}{*}{ p-Value } \\
\hline & $\mathbf{n}$ & $\%$ & $\mathbf{n}$ & $\%$ & \\
\hline \multicolumn{6}{|c|}{ Are you comfortable discussing organ donation? } \\
\hline Comfortable & 182 & 94 & 155 & 82 & \multirow{2}{*}{$<0.001^{*}$} \\
\hline Uncomfortable & 11 & 6 & 35 & 18 & \\
\hline \multicolumn{6}{|c|}{ Do you think organ donation disfigures the body? } \\
\hline Disfigures & 47 & 24 & 41 & 22 & \multirow{2}{*}{0.52} \\
\hline Does not disfigure & 146 & 76 & 149 & 78 & \\
\hline \multicolumn{6}{|c|}{ Do you think organ donation needs to be promoted? } \\
\hline Needs Promotion & 166 & 86 & 166 & 87 & \multirow{2}{*}{0.70} \\
\hline Does not need Promotion & 27 & 14 & 24 & 13 & \\
\hline \multicolumn{6}{|c|}{ Do you think payment for donation of organs is ethical? } \\
\hline Ethical & 37 & 19 & 68 & 36 & \multirow{2}{*}{$<0.001^{*}$} \\
\hline Unethical & 156 & 81 & 122 & 64 & \\
\hline \multicolumn{6}{|c|}{ Are you aware of the current laws in Pakistan concerning organ donation? } \\
\hline Aware & 27 & 14 & 31 & 16 & \multirow{2}{*}{0.53} \\
\hline Unaware & 166 & 86 & 159 & 84 & \\
\hline
\end{tabular}

*Indicates statistical significance

When asked to identify potential barriers to organ donation in Pakistan, both medical and non-medical students most commonly cited lack of awareness $(60 \%$ vs. $57 \%$ ), fear of receiving inadequate care (62\% vs. $63 \%$ ) and family objections (60\% vs. $51 \%$; Figure 1). More medical than non-medical students considered religious beliefs to be a barrier (51\% vs. $39 \%$ ). Cultural beliefs and the lack of financial incentives were less commonly regarded by both as prevalent barriers to donation (35\% vs. $29 \%$ and $19 \%$ vs. $15 \%$, respectively).

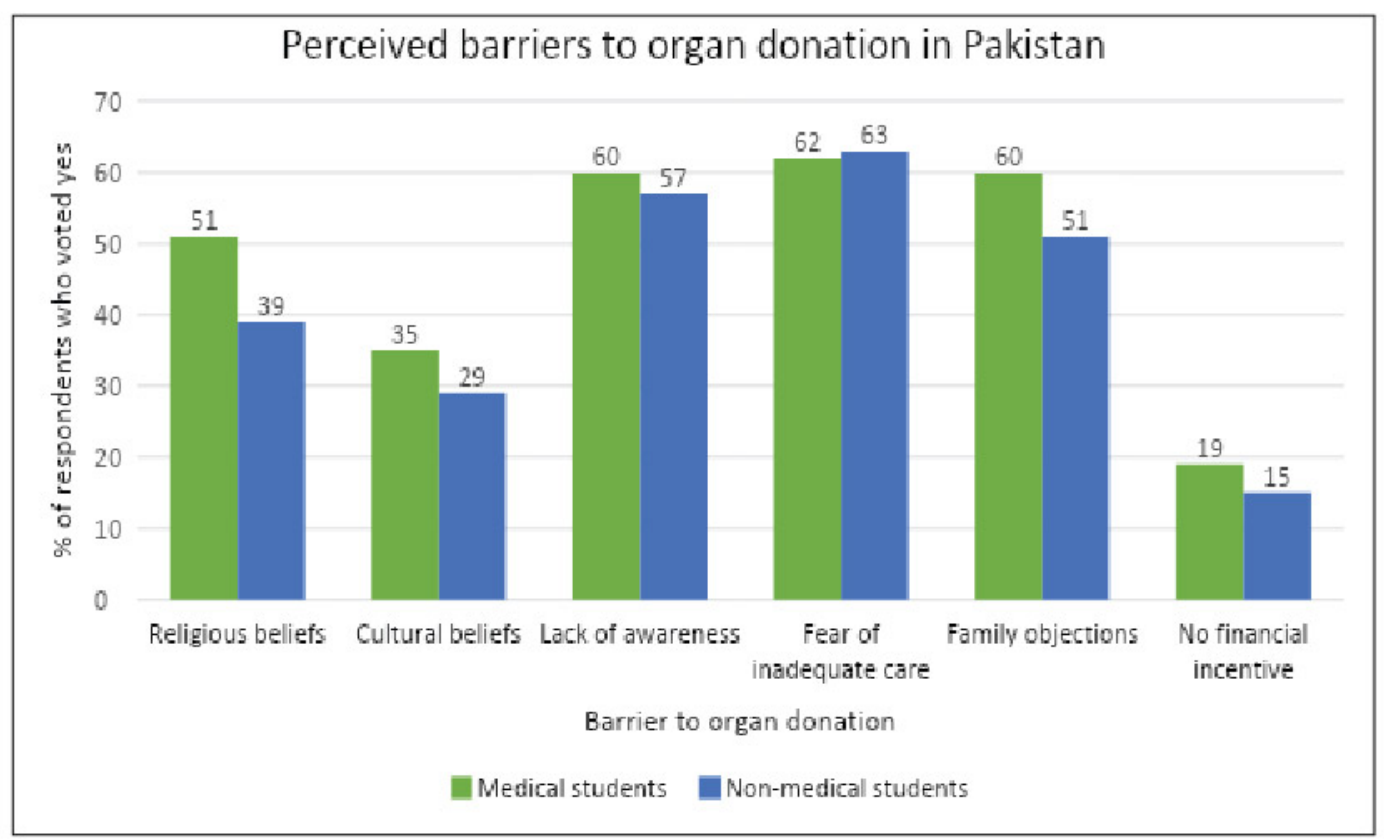

Figure 1: Barriers to organ donation in Pakistan, as identified by medical and non-medical university students

Overall, for the study population, the most common source of knowledge regarding organ donation (Figure 2) was social media (65\%), followed by university (54\%), family/friends (48\%) and television
(45\%). Public health campaigns and newspapers were a source for fewer respondents $(33 \%$ and $21 \%$ respectively). 


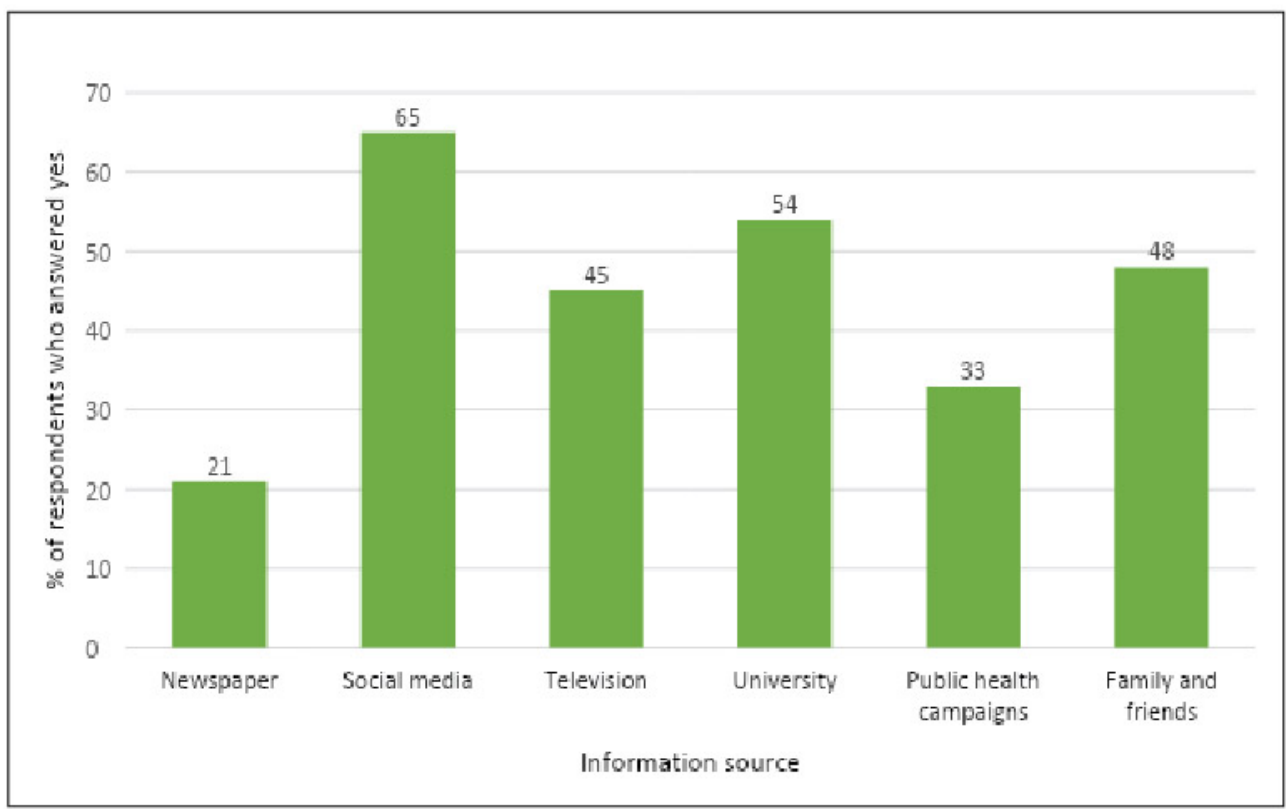

Figure 2: Sources of information regarding organ donation, as cited by study participants.

\section{DISCUSSION}

Approximately half of the study population expressed willingness to donate, which was drastically less than the number of people who were aware of the concept of organ donation. Since, Pakistan is in its initial stages of ethical organ transplantation' but the need for donations amongst patients with end-stage organ failure has been at a gradual, if not exponential, increase since the inception of the country in 1947. The lack of awareness, coupled with ineffective laws pertaining to the subject, has been a major contributing factor in the laboured progression of organ donation. This research highlighted the importance of knowledge amongst people of Pakistan with reference to medical and non-medical students. The results show a unique response to a subject that is currently struggling to redeem itself from the realm of being somewhat taboo in the subcontinent ${ }^{3}$.

Moreover, only $2 \%$ of the total respondents owned an organ donor card - a necessity to be able to donate organs in Pakistan. Research conducted in China ${ }^{10}$ and Japan ${ }^{11}$ shows a marked difference in the attitudes of medical versus non-medical students with the former being more willing to donate. However, this was not evident in our findings and could be due to the increased public awareness created by the Transplantation Society of Pakistan" and introduction of the "Transplantation of Human Organs and Tissues Bill 2007" which was proposed in the National Assembly of Pakistan and further amended in 2016 after an increased interest in legal and ethical organ donation was shown ${ }^{13}$. Medical students are taught about the benefits of organ donation regardless but implementation of this bill and the subsequent media coverage that it was given was necessary to not only promote legal and ethical organ donation but also to dispel myths regarding the process in the population from the non-medical background. As emphasized by Tarzi et al. presumed consent legislation greatly impacts organ procurement levels and that the fear of committing an illegal action due to unawareness of the exact laws may be the reason as to why almost half of the population in our study was not keen on donation ${ }^{14}$.

In contrast to many studies conducted on this topic in various parts of the world, our results did not find gender, socioeconomic status, or religion to be significant ${ }^{3,15}$. Agrawal et al. commented on Saudi Arabia, a Muslim dominated region like Pakistan, and emphasises that the fear of mutilation and lack of religious backing from local scholars leads to disparity amongst the willingness to donate versus the actual number of donors ${ }^{16}$. However, the progression in scientific advancements in the last few decades that show transplantation causes more benefits than harm could be why recently more scholars from the largest religions of the world support this practice ${ }^{17}$. Although our research indicates otherwise, it has been suggested that females are more bound to donate organs compared to males due to a longer duration of being in possession of healthy organs i.e., realizing that males are more prone to end-stage organ failure at an earlier age. However, with the rising advancements in medicine, it seems likely that the results obtained may be indicating a new era of increased availability and readiness about the give and take 
of healthy organs regardless of gender ${ }^{18}$.

It was shown that someone who was comfortable discussing organ donation with friends and family was over twice as likely to become an organ donor as compared to those who did not. This finding was deemed significant in our analysis and further emphasised the need for a holistic approach to teaching families about the benefits regarding the practice. Krupic et al. studied the causes of organ donation refusal in Sweden and reported high numbers of extended family and next of kin refusing to allow their relatives to donate organs ${ }^{19}$. For religious reasons or otherwise, this has been a similar trend in many places. One way for increasing willingness among families to talk about donation is to educate medical practitioners so that they may encourage patients to clear any doubts regarding the process ${ }^{20}$.

Another significant finding was that more non-medical students believed that payment for procurement of organs was ethical, as compared to medical students. A medical student's future livelihood depends on monetary profitability from surgical procedures or from referring a patient to the required surgical department but most medical students, over $80 \%$, still considers the act wrong. Quite possibly, due to the everyday exposure of actual patients, health may no longer seem like a commodity but more of a necessity in a world that continuously requires the altruism of the healthy to assist in the amelioration of the sick.

\section{CONCLUSION}

Our study showed some differences in the knowledge and attitude of students of medical and non-medical fields in regards to the practice of organ donation. This shows the need for a more comfortable and detailed approach in the pathway to organ donation, for medical and non-medical students, in order to ensure that future generations are keener and more informed about organ donation.

\section{ACKNOWLEDGEMENTS}

We would like to thank the students of Dow Medical College, Ziauddin University, Institute of Business Administration, NED University and the rest of the students from across Karachi, Pakistan for their participation.

\section{CONFLICT OF INTEREST}

The authors declare no conflict of interest.

\section{ETHICS APPROVAL}

The ethics approval for the study was obtained from the Ethical Board of the Research Council of Pakistan.

\section{PARTICIPANT CONSENT}

Written consents were obtained from the participants of the study.

\section{AUTHORS' CONTRIBUTION}

All authors contributed equally in this study.

\section{REFERENCES}

1. Global Observatory on Donation and Transplant [Internet]. 2017 [cited 2021 Apr 16]. Available from http://www.transplant-observatory.org/summary/

2. Ansari MN. Editorial organ donation: Ethics. J Coll Physicians Surg Pak. 2007;17(9):517-518.

3. Khalid F, Khalid AB, Muneeb D, Shabir A, Fayyaz D, Khan $M$. Level of knowledge and attitude regarding organ donation: a community-based study from Karachi, Pakistan. BMC Res Notes. 2019;12(1):1-5.

4. Tumin M, Tafran K, Tang LY, Chong MC, Jaafar NI, Satar NM, et al. Factors associated with medical and nursing students' willingness to donate organs. Medicine (Baltimore). 2016; 95(12):1-4.

5. Lei L, Deng J, Zhang H, Dong H, Luo Y. Level of organ donation-related knowledge and attitude and willingness toward organ donation among a group of university students in Western China. Transplant Proc. 2018;50(10):2924-2931.

6. Liu C, Liu S, Liu B. Medical students' attitudes toward deceased organ donation in China: A cross section cohort study. Transplant Proc. 2020;52 (10):2890-2894.

7. Sellers MT, McGinnis HS, Alperin M, Sweeney JF, Dodson TF. Deterrents to organ donation: a multivariate analysis of 766 survey respondents. J Am Coll Surg. 2018;226(4):414-422.

8. Gauher ST, Khehar R, Rajput G, Hayat A, Bakshi B, Chawla $\mathrm{H}$, et al. The factors that influence attitudes toward organ donation for transplantation among UK university students of Indian and Pakistani descent. Clin Transplant. 2013;27(3):359-367.

9. Naqvi SA, Ali B, Mazhar F, Zafar MN, Rizvi SA. A socioeconomic survey of kidney vendors in Pakistan. Transplant Int. 2007;20(1 1):934-939.

10. Zhang L, Liu W, Xie S, Wang X, Woo SM, Miller AR, Yuan D, et al. Factors behind negative attitudes toward cadaveric organ donation: A comparison between medical and non-medical students in China. Transplantation. 2014;98(8):78-79.

11. Hamano I, Hatakeyama S, Yamamoto H, Fujita T, 
Prevalence and Predictors of Willingness and Attitudes towards Organ Donation among Medical and Non-Medical University Students in Karachi

Murakami R, Shimada M, et al. Survey on attitudes toward brain-dead and living donor transplantation in medical students: a cross-sectional study in Japan. Chin Exp Nephrol. 2020;24(7):638-645.

12. Transplantation Society of Pakistan ${ }^{\odot 2009}$. Need for public education on deceased organ donation stressed 2016 [Internet]. Transplantation Society of Pakistan [cited 2021 Apr 16]. Available from: http://tx-society-pk.org/Need-for-public-education-next-01.html

13. Junaidi I. Organ donor bill sent to yet another standing committee. Dawn. 2016. Available from https://www.dawn.com/news/1299558

14. Tarzi M, Asaad M, Tarabishi J, Zayegh O, Hamza $\mathrm{R}$, Alhamid A, et al. Attitudes towards organ donatimon in Syria: a cross-sectional study. BMC Med Ethics. 2020;21 (1):1-10.

15. Tamuli RP, Sarmah S, Saikia B. Organ donation"attitude and awareness among undergraduates and postgraduates of North-East India". J Family Med Prim Care. 2019; 8(1):130-136.

16. Agrawal S, Binsaleem S, Al-Homrani M, Al-Juhay- in A, Al-Harbi A. Knowledge and attitude towards organ donation among adult population in Al-Kharj, Saudi Arabia. Saudi J Kidney Dis Transpl. 2017;28 (1):81-89.

17. Krupic F. The impact of religion and provision of information on increasing knowledge and changing attitudes to organ donation: An intervention study. J Relig Health. 2019;14:1-14.

18. Boulware LE, Rather LE, Sosa JA, Cooper LA, LaVeist TA, Pow NR. Determinants of willingness to donate living related and cadaveric organs: identitying opportunities for intervention. Transplantation. 2002;73(10):1683-1691.

19. Krupic F, Westin O, Hagelberg M, Sköldenberg O, Samuelson K. The influence of age, gender and religion on willingness to be an organ donor: Experience of religious Muslims living in Sweden. J Relig Health. 2019;58(3):847-859 .

20. Hasa H, Zehra A, Riaz L, Ria R. Insight into the knowledge, attitude, practices, and barriers concorning organ donation amongst undergraduate students of Pakistan. Cureus. 2019;1 1(8):1-12.

108

PAKISTAN JOURNAL OF MEDICINE AND DENTISTRY 2021, VOL. 10 (03)

https://doi.org/10.36283/PJMD10-3/018 